$\mathrm{H}-\mathrm{IE}$ is in progress, with a view to prevention of West syndrome by early administration of ACTH [Millichap JJ, prepublication observations].

\author{
References \\ 1. Millichap JG, Bickford RG. JAMA. 1962;182(5):523-527. \\ 2. Lux AL, et al. Lancet Neurol. 2005 Nov;4(11):712-7. \\ 3. Gano D, et al. Pediatr Neurol. 2013 Dec;49(6):401-5. \\ 4. Suzuki M, et al. Epilepsia. 2003 Mar;44(3):443-6. \\ 5. Kato T, et al. Epilepsia. 2010 Dec;51(12):2392-6.
}

\title{
LONG-TERM OUTCOME OF JUVENILE MYOCLONIC EPILEPSY
}

Investigators at Epilepsy Centers in Berlin, Germany, performed a retrospective study of seizure outcome in 66 patients with juvenile myoclonic epilepsy (JME) after a mean follow-up time of 44.6 years (20-69 years); $59.1 \%$ of patients remained seizure-free for at least 5 years before the last contact. Of seizure-free patients, 28 (71.8\%) remained on AEDs and $11(28.2 \%)$ were off medication for at least the last 5 years. Absence seizures at onset were an independent predictor of an unfavorable outcome and JME persistence. (Senf P, et al. Prognosis of juvenile myoclonic epilepsy 45 years after onset. Seizure outcome and predictors. Neurology 2013 Dec 10;81(24):2128-33).

COMMENTARY. JME is usually described as a chronic disorder requiring lifelong therapy [1]. In contrast, recent long-term follow-up studies point to a more favorable prognosis, allowing cautious withdrawal of medication after long seizure control [2]. In an editorial comment, a trial of older medications, including primidone and acetazolamide, is recommended in patients with refractory JME [3].

\section{References}

1. Penry JK, et al. Epilepsia. 1989;30 Suppl 4:S19-23.

2. Camfield CS, Camfield PR. Neurology. 2009 Sep 29;73(13):1041-5.

3. So NK. Neurology. 2013 Dec 10;81(24):2132.

\section{ENCEPHALOPATHIES}

\section{ENCEPHALOPATHIC SUSAC SYNDROME}

Investigators from Tubingen and Munster, Germany, report the case of a 32-yearold woman who at 32 weeks of pregnancy developed a change in personality, disorientation, ataxia, dysarthria, and hemispasticity. MRI showed multiple diffuse T2intense lesions, many involving the corpus callosum. CSF showed mild lymphocytic pleocytosis $(13$ cells $/ \mathrm{mcl})$ and elevated protein $(1,800 \mathrm{mg} / \mathrm{l})$ and no oligoclonal bands. A bluish, net-like exanthema on trunks and legs was diagnosed as livedo racemosa. Weeks later, she was readmitted with visual field loss and ischemic damage to both retinae, and bilateral hearing loss. With a diagnosis of Susac syndrome, IV cyclophosphamide, the standard treatment, was not instituted because of risk of permanent infertility. A combination of prednisolone, IV immunoglobulins, mycophenolate mofetil, and methotrexate provided a sustained control of symptoms. (Engeholm M, et al. 
Encephalopathic Susac's syndrome associated with livedo racemosa in a young woman before the completion of family planning. BMC Neurol 2013 Nov 25;13:185).

COMMENTARY. Susac syndrome (SS)[1] consists of a triad of encephalopathy, branch retinal artery occlusions and hearing loss. Associated abnormalities include multifocal corpus callosal lesions on MRI [2], resembling a vasculitis, and autoimmune disorder such as juvenile dermatomyositis. Headache is usually constant but was absent in the above case. Women are affected more often than men $(3: 1)$; the age of onset ranges from 7 to 72 years, but ages 20-40 are most vulnerable [3]. SS is an autoimmune endotheliopathy that responds to treatment with immunosuppressants, steroids, cyclophosphamide, and IV immunoglobulin, with aspirin as an adjunct [2][4].

\section{References}

1. Susac JO, et al. Neurology. 1979 Mar;29(3):313-6.

2. Susac JO, et al. J Neurol Sci. 2007 Jun 15;257(1-2):270-2.

3. Rennebohm R, et al. J Neurol Sci. 2010 Dec 15;299(1-2):86-91.

4. Millichap JG. Neurological Syndromes. New York: Springer; 2013:279.

\section{INTERFERON BIOMARKERS IN AICARDI-GOUTIERES SYNDROME}

Investigators at University of Manchester, UK, and multiple international centers studied interferon-related biomarkers in patients with Aicardi-Goutieres syndrome (AGS). Of 82 patients with AGS, $74(90 \%)$ had a positive interferon score. The measurement of an interferon score might be used to assess efficacy of anti-inflammatory therapy. (Rice GI, Forte GMA, Szynkiewicz M, et al. Assessment of interferon-related biomarkers in Aicardi-Goutieres syndrome associated with mutations in TREX1 (and any of six genes): a case-control study. Lancet Neurol 2013 Dec;12(12):1159-69).

COMMENTARY. Aicardi-Goutieres syndrome is an early-onset familial encephalopathy characterized by brain atrophy, microcephaly, spasticity, dystonia, psychomotor retardation, chronic CSF lymphocytosis, basal ganglia calcification, autoimmune disorders such as chilblains (pernio), and increased interferon-alpha in the CSF and serum [1][2]. High mortality in the first year is common. An early active stage of the disease followed by a period of attenuation correlates with higher levels of interferon activity in infancy and lower levels with increasing age.

\section{References.}

1. Aicardi J, Goutieres F. Ann Neurol. 1984 Jan;15(1):49-54.

2. Stephenson JB. Eur J Paediatr Neurol. 2008 Sep;12(5):355-8. 